\title{
'Hacking' the pandemic: turning online work challenges into learning with IMPACT
}

Caroline Keenan

University of Exeter

\section{Constantine Manolchev}

University of Exeter

Keywords: learning design; experiential learning; hacks; learning community; Covid-19.

\section{The challenge}

The challenge presented by the pandemic and its effect on everyone in university education was acute. Our students in the Law and Business Schools at the University of Exeter were thrust into physical isolation and anxiety, away from their expectation of learning as an on-campus, social and timetabled endeavour. Although the transition to online delivery mitigated against fundamental disruption to learning, our students struggled with motivation, distractions and anxiety, exacerbated by the need for some to work across different time-zones (Baber, 2020; Wildman et al., 2020).

We academics also faced a myriad of challenges (Gomes et al., 2020). Locked out of our offices and missing our students and colleagues, we were talking to dark screens from our kitchen tables. We felt that we were losing our identity as educators and becoming crisis managers. We needed to move away from patterns of interaction characterised by worry and lack of engagement, to return to the joyful collective endeavour of learning. The challenge we encountered was situated in the learning experience of our undergraduate students; however, we feel that the pedagogic value of our intervention transcends disciplinary boundaries and can be successfully applied to blended delivery in a more general educational context. 


\section{The response}

\section{Inception}

Before lockdown, we had talked about creating a hackathon (termed 'IMPACT' for its intended outcomes and stylised in capitals) for our second year students. Although on different degrees run by our respective departments - specifically, a BSc Business, an LLB Law and Business, and a BBL in Business Law - our students share a number of modules in their second year. We had intended to use the hackathon to establish a supportive learning community, yet we now hoped it would also serve as a pedagogic device (Bernstein, 2000), that is, a means of transmitting knowledge and re-contextualising learning in a digital environment.

Hackathons are well established in the field of computer programming (Maaravi, 2020) and involve participants working intensely in small groups, over a short time period, towards a technological solution to a problem (Porter et al., 2017). Their use has gradually become more pluralistic, entering many other disciplines (Artiles and Wallace, 2013). This has seen a broadening of the definition of hackathons to 'creative marathons' with a 'learn-buildshare mantra' (Goodman and Radu, 2020) that are time-limited, group-based and problem-solving (Tauberer, 2017). In addition to being hosted by governments, NGOs, businesses, museums and libraries (Turner et al, 2021), hackathons are an ideal tool for educators. They can build a 'hobby space' for idea creation outside of other academic pressures, such as assessments (Artiles and Wallace, 2013). This liberates students from a 'fear to fail' environment, developing an engaging and creative atmosphere that is likely to lead to effective student learning. Students work with each other to build their skills beyond 'toy' problems and produce valued solutions to them. This intense period of shared goals and experiences outside of the normal routine creates an instant community amongst participants. Hackathons reinforce students' belief in themselves, each other and their discipline, making them the ultimate win-win educational event (Munro, 2016).

\section{Preparation}

We first needed an identity for our hackathon, and with it a problem for our students to 'hack'. For the hackathon to be an effective 'reset' button for us, the 'problem' under consideration had to be real and immediate, link to the subjects they were studying - Law 
and Business - and allow students to reach new solutions collaboratively. The name had to signal utility, whilst the context had to feature a range of challenges and issues, inviting problem solving.

We chose the food and drink industry, which has been severely impacted by the coronavirus pandemic (OECD, 2020; UK Parliament, 2020), and asked businesses in the region for problems our students could 'hack'. We selected three: Rick Stein, Wild Harbour and Swannacott Manor. All were looking for ways to 'put their services out there' in the new, online-only context. Our students, who were studying marketing and client-focused, transactions, were perfect for the task.

\section{Delivery}

IMPACT was organised around the four common characteristics of hackathons (Lara and Lockwood, 2016, p. 486):

- 'Participants are organized into small groups that work intensely'. We created 28 interdisciplinary teams, allocating each to one of four business challenges. We cleared their timetables of other classes and assessment deadlines to enable students' exclusive focus.

- 'A short time frame in which the project is taken from concept to prototype. Our students had five days from the release of their challenge to present a video 'pitch' of their solution to the business involved and face questions by the judging panel on the final day.

- 'A centralized location where teams meet, work, and share resources'. We created a dedicated Moodle page containing all the information for the week, including briefs of the task, timetables and links, information about the businesses involved and the workshops we were holding. In the absence of physical meeting spaces, we created private channels for each group in Microsoft Teams (a familiar system, within the university by then).

- 'Support provided by organizers and sponsors'. During the week student groups met with their business 'client' to understand their needs beyond the problem brief provided. They also had skills workshops, links to additional resources, and access to academic and technical helpdesks. 


\section{Result}

Hackathons create an instant community full of energy and engagement (Porter et al, 2017). The word 'fun' was used repeatedly by students, businesses and colleagues during the week. Our student groups presented original and, in some cases, dazzling ideas. The businesses involved gave individual feedback, finding usable ideas in each pitch. We all shared the unique positive experience of those five days.

IMPACT is definitely here to stay.

\section{Recommendations}

If trying something similar, we recommend that you:

- Start online. Although thinking it was 'plan B', working online freed us from geographic and timetabling constraints to plan a week that fulfilled our objectives, with the right collaborators.

- Then blend. Link the space to the learning, for example, the ideal space for collaboration was MS Teams, but campus is better for skills workshops.

- Make it compulsory, but market it as an opportunity. It cannot be a choice to take part, as this is an unfamiliar part of the curriculum, but be serious in your efforts to inform and excite students about what they will take part in.

- Recognise the value of a diverse staff team in planning.

- Timetabling. Arrange it at a time during the academic year when there is a dip in energy.

- Use every type of learning resource to 'scaffold' learning. House them in a dedicated online space.

- Show you take students seriously. Link it explicitly to their learning, their professional development and give them a chance to shine.

- Create an event that you enjoy. It is why we all came into teaching in the first place. 


\section{References}

Artiles, J. A. and Wallace, D. R. (2013) 'Borrowing from hackathons:

overnight designathons as a template for creative idea hubs in the space of handson learning, digital learning, and systems re-thinking', WEEF 2013 Cartagena, Available at: https://acofipapers.org/index.php/eiei/article/view/1434/1439 (Accessed: 15 July 2021).

Baber, H. (2020) 'Determinants of students' perceived learning outcome and satisfaction in online learning during the pandemic of COVID-19', Journal of Education and eLearning Research, 7(3), pp.285-292. Available at: https://doi.org/10.20448/journal.509.2020.73.285.292 (Accessed 24 August 2021).

Bernstein, B. (2000) Pedagogy, Symbolic Control and Identity. Revised edn. Oxford: Rowman \& Littlefield Publishers.

Gomes, M., Manolchev, C., Nyfoudi, M. and Pustelnikovaite, T. (2020) 'Is it all "Zoom and gloom" for higher education?', Futures of Work, Available at: https://futuresofwork.co.uk/2020/05/07/is-it-all-zoom-and-gloom-for-highereducation-reflections-in-the-midst-of-a-pandemic/ (Accessed: 10 July 2021).

Goodman, T. and Radu, A.I. (2020) 'Learn-apply-reinforce/share learning: hackathons and CTFs as general pedagogic tools in higher education, and their applicability to distance learning' (Arxiv pre-print), Available at: http://dx.doi.org/10.13140/RG.2.2.21810.43205 (Accessed: 24 August 2021).

Lara, M. and Lockwood, K. (2016) 'Hackathons as community-based learning: a case study', TechTrends, 60, pp.486-495. Available at: https://doi.org/10.1007/s11528016-0101-0 (Accessed: 24 August 2021).

Maaravi, Y. (2020) 'Using hackathons to teach management consulting', Innovations in Education and Teaching International, 57(2), pp. 220-230. Available at: https://doi.org/10.1080/14703297.2018.1563868 (Accessed 24 August 2021). 
Munro, D. (2015) 'Hosting hackathons a tool in retaining students with beneficial side effects', Journal of Computing Sciences in Colleges, 30(5), pp 46-51. Available at: https://doi.org/10.1080/14703297.2018.1563868 (Accessed 24 August 2021).

OECD (2020) Food supply chains and COVID-19: impacts and policy lessons. Available at: https://www.oecd.org/coronavirus/policy-responses/food-supply-chains-andcovid-19-impacts-and-policy-lessons-71b57aea/ (Accessed 24 August 2021).

Porter, E., Bopp, C., Gerber ,E. and Voida, A. (2017) 'Reappropriating hackathons: the production work of the CHI4Good Day of Service', Proceedings of the $2017 \mathrm{CHI}$ Conference on Human Factors in Computing Systems, Denver Colorado, USA 6-11 May. Available at: https://doi.org/10.1145/3025453.3025637 (Accessed 13th July 2021).

Tauberer, J. (2017) How to Run a Successful Hackathon. Available at: https://hackathon.guide/ (Accessed: 13 July 2021).

Turner, A.J., Hardin, C.D. and Berland, M. (2021) 'Hackathons and 'i'dentities: museum visitor identities in other informal learning environments', Visitor Studies, (Ahead of Print), pp.1-19. Available at: https://doi.org/10.1080/10645578.2021.1925505 (Accessed: 16 July 2021).

UK Parliament (2020) Effects of COVID-19 on the food supply system. Available at: https://post.parliament.uk/effects-of-covid-19-on-the-food-supply-system/ (Accessed 24 August 2021).

Wildman, J.L., Nguyen, D.M., Duong, N.S. and Warren, C. (2021) 'Student teamwork during COVID-19: challenges, changes, and consequences', Small Group Research, 52(2), pp.119-134. Available at: https://doi.org/10.1177\%2F1046496420985185 (Accessed 24 August 2021). 


\section{Author details}

Caroline Keenan is the Director of Education for the University of Exeter Law School in Cornwall. She is an inter-disciplinary researcher, examining how people use and understand law in action. Her current research projects are interdisciplinary, working particularly with colleagues in the Business School, Academic Development and the TEL team and focussing on learning design for inclusive practice and widening participation.

Constantine Manolchev is a Programme Director for the University of Exeter Business School in Cornwall. He is interested in the 'dark side' of organisations: violence, bullying, harassment and negative acts. Constantine also researches the wider, neoliberal labour market contexts in which organisations are situated focusing especially on precarious work. 